\title{
İnsan Kaynakları Bilgi Sistemlerine Yönelik Algıların Teknoloji Kabul Modeli İle İncelenmesi
}

\author{
The Investigation of Perceptions for Human Resource Information Systems via \\ Technology Acceptance Model
}

\author{
Mustafa ARAS ${ }^{1}$, Yasemin ÖZDEMIR' ${ }^{1}$, Serkan BAYRAKTAROĞLU ${ }^{1}$
}

\begin{abstract}
ÖZET
Insan kaynakları bilgi sistemleri (IKBS) işletmelerde çeşitli nedenlerle giderek daha fazla kullanılmaya başlanmasına rağmen başarısı birçok faktöre bağlıdır. İKBS başarısını etkileyen faktörlerden biri de kullanıcılardır. Bu çalışmanın amacı, insan kaynakları bilg sistemleri kullanıcılarının sisteme yönelik algılarııın teknoloji kabul modeli ile incelenmesidir. Teknoloji Kabul Modeli Davis (1985) tarafından geliştirilmiş ve dışsal değişkenler, algılanan fayda, algılanan kullanım kolaylığı, kullanıma yönelik tutum, davranışa yönelik niyet ve gerçekleşen davranış değişkenlerinden oluşmaktadır. Bu çalışmada dışsal değişken olarak yazılım şirketi IKBS eğitimi, kurum içi IKBS eğitimi, yazııım bilgisi, donanım bilgisi, programlama bilgisi modele dâhil edilmiş ve değişkenler arasındaki etki incelenmiştir. Araştırma kapsamında Marmara bölgesinde çalışan 302 IKBS kullanıcısına standardize anket uygulanmıs, daha sonra anketler analiz edilmiş ve bulgular değerlendirilmişstir. Araştırma sonucuna göre; yazılım şirketi İKBS eğitimi, kurum içi IKBS eğitimi, yazııım bilgisi, donanım bilgisi, programlama bilgisi değişkenlerinin algılanan kullanım kolaylığı ve algılanan fayda üzerinde pozitif etkiye sahiptir. Algılanan kullanım kolaylığı algılanan fayda üzerinde pozitif etkiye sahiptir. Algılanan kullanım kolaylığı ve algılanan fayda niyet üzerinde; niyet ise gerçekleșen davranıș (IKBS kullanımı) üzerinde pozitif etkiye sahiptir. Tutumun niyet üzerinde etkisinin olduğu düşünülmesine rağmen araştırma bulguları bu düşünceyi desteklememiştir.
\end{abstract}

Anahtar Kelimeler: İnsan kaynakları bilgi sistemi, teknoloji kabul modeli, IKBS eğitimi, bilgisayar bileşenleri bilgisi

\section{GíRiş}

Yetenekli insan sayısının az olması, bilgi ekonomisine geçiş ve artan rekabet işletmelerin işgücü verimliliğine daha fazla önem vermesini zorunlu kılmaktadır. İşücü verimliliğini arttırmanın yolu insan kaynakları ile ilgili doğru kararlardan geçer. Çünkü iyi kararlar, kaliteli bilgiye dayanır (Winkler vd., 2013). Bu yüzden insan kaynakları ve örgütsel etkinlik ile ilgili kararlar işletmelerin başarılı olmalarında hayati öneme sahiptir. İşletmeler hızlı ve iyi kararlar almak için maliyetli olmasına rağmen bilgi sistemlerini kullanmakta fakat arzu edilen başarıyı elde edememektedirler. Davis ve Venkatesh (2004) yaptıkları bir çalışmada bilgi sistemleri projelerinin \%24 oranında başarısız olduğunu, \%17 oranında beklenen maliyetlerden

\begin{abstract}
Despite human resource information systems (HRIS) being used more and more for various reasons in organizations, its success depends on many factors. One of the factors affecting the success of HRIS is also users. The purpose of this study is investigate perceptions for human resource information systems (HRIS) via technology acceptance model. Technology acceptance model (TAM) introduced by Davis (1985) which attempts to explain end users to computing technologies. TAM involved external variables, perceived ease of use, perceived usefulness, attitudes, behavioral intention and actual system use. In this study as an external variables software company HRIS training, in house HRIS training, software knowledge, hardware knowledge and programming knowledge has been included in the model and effect between variables were examined. Standardized questionnaire was applied to 302 HRIS users working in the Marmara region. After analyzing the questionnaires, the results were evaluated. As a result, software company HRIS training, in house HRIS training, software knowledge, hardware knowledge and programming knowledge have positive effect on perceived ease of use and perceived usefulness. Perceived ease of use and perceived usefulness have positive effect on behavioral intention, behavioral intention has positive effect on actual system use (HRIS usage). Although it is considered that attitudes have an impact on behavioral intention, in this study these findings were not supported.
\end{abstract}

Keywords: Human resource information system, technology acceptance model, HRIS education, computer components information

daha maliyetli olduğunu bulmuşlardır. Öyle ki bilgi sistemlerinin başarılı olmasında insan faktörünün en önemli unsur olduğu vurgulanmaktadır (Martinsons ve Chong, 1999). Bu sistemlerin başarısız olmasında teknolojik problemlerin toplam problemlerin içindeki payı \%10'dan azdır. Bunun yanı sıra kullanıcı beklentilerini karşılayan sistemlerin başarılı olduğu ifade edilmektedir (Aras ve Bayraktaroğlu, 2013).

Teknoloji Kabul Modeli (TKM), bilgi sistemlerinin kullanım niyetini önceden tahmin eden, kullanıcı kabulünü teyit eden ve alandaki en önemli kabul modelidir (Winkler vd., 2013). TKM; dışsal değişkenler, algılanan fayda, algılanan kullanım kolaylığı, kullanıma yönelik tutum, davranışa yönelik niyet ve gerçekleşen davranış değişkenlerinden oluşmaktadır. 
Insan kaynakları departmanında insan kaynakları bilgi sistemlerinin kullanımı giderek yaygınlaşmaktadır. Bu çalışmada insan kaynakları bilgi sistemleri kullanıcılarının sisteme yönelik algıları teknoloji kabul modeli ile incelenmiştir. Bu kapsamda öncelikle insan kaynakları bilgi sistemlerinden, sistemin amaç ve öneminden bahsedilmiş, sonrasında ise teknoloji kabul modeli tanıtılmıştır. Son bölümde ise araştırma kurgusu ve bulgularına yer verilmiştir.

\section{INSAN KAYNAKLARI BILGI SISTEMLERI}

İnsan Kaynakları Bilgi Sistemleri (IKBS) örgütsel performans ve verimliliği arttırmak için önemli bir unsur haline gelmiştir. Başlangıçta personel yönetimi ile ilgili işlemsel süreçleri desteklemek ve operasyonları kontrol etmek için kullanılan bu sistemler günümüzde daha gelişmiş uygulamalarla rekabet edebilirliğe katkı sağlamak ve karar verme sürecini geliştirmek amacıyla kullanılmaktadır (Haines ve Petit, 1997). İnsan kaynaklarının yönetimi sürecinde etkinliği artırmak için kullanılan bu sistemler, organizasyonlarda insan kaynaklarına yönelik bilgileri toplamak, depolamak, kullanmak, irdelemek ve bilgi paylaşımını sağlamak amacıyla dağıtmak için kullanılan sistemlerdir (Tannenbaum, 1990).

İnsan kaynakları bilgi sistemleri bilgi toplumunda işletmeler için önemlidir ve rekabet avantajı sağlamada işletmeler için vazgeçilmez bir nitelik kazanmaktadır. İKBS'nin en temel amacı sistem kullanıcılarına bilgi formunda hizmet sunarak verilere hızı ılaşım sayesinde rekabet avantajı sağlamasıdır. Gerektiğinde insan kaynakları departmanının ihtiyaç duyduğu bilgileri sağlamak (Tannenbaum, 1990) ve insan kaynakları kararlarını desteklemek (Kovach ve Carthcart, 1999: 275) IKBS'nin amaçlarındandır. Bunlara ek olarak İKBS, çalışanların; seçilmesi ve istihdam edilmeleri, görevlerinin belirlenmesi, performanslarının değerlendirilmesi, ücret ve diğer ödemelerin analizi, yetiştirme ve geliştirme, sağlık ve sosyal güvenlik sorunlarının çözümü gibi konularda organizasyona destek sağlamaktadır (Bayraktaroğlu ve Tunçbilek, 2002). Bununla beraber insan kaynakları bilgi sistemleri yönetsel maliyetleri azaltmaktadır. İşletmeler teknolojinin yeni fikirleri cesaretlendirdiğini ve orta sınıf yönetim ihtiyacını ortadan kaldırdığını fark etmişlerdir. Özel ve kamu sektör örgütlerinin faaliyetlerine bakarak IKBS'nin insan kaynakları departmanını küçültmek ve insan kaynakları fonksiyonlarını yeniden tasarlamak için kullanıldığını söylemek de mümkündür (Kovach ve Carthcart, 1999: 276).

IKBS'nin hızlı bilgi akışı, veri doğruluğunda artış, daha kullanışlı ve kaliteli sonuçlar, verimlilikte artış, personel iletişiminin daha iyi olması, personel güçlendirme, plan ve programların geliştirilmesi gibi yararları vardır (Haines ve Petit, 1997; Beckers ve Bsat, 2002; Beadles vd., 2005; Chandra, 2009).

Bu sistemlerin kullanılmasının birçok faydasına rağmen kısıtları da mevcuttur. IKBS'nin kurulmasının maliyetli olması (Beckers ve Bsat, 2002), yetersiz sermaye ve üst yönetimin sistem kullanımını desteklememesi (Kovach ve Cathcart, 1999), sistemin kurulumu sırasında sistem yazılımcılarının uzun süren çalışmaları ve verilerin sisteme aktarılmasının uzun bir zaman gerektirmesi, sistem kurulumu sonrasında ortaya çıkan sistem destek maliyetleri (Lengnick-Hall ve Moritz, 2003) ve veri güvenliği ve gizliliği bilgi sistemlerinin kısıtlarıdır.

\section{TEKNOLOJI KABUL MODELI}

Teknoloji Kabul Modeli (TKM); Davis tarafından geliştirilen, kullanıcıların davranışlarını tahmin yoluyla bilgi sistemleri kabulünü etkileyen faktörleri açıklayan bir modeldir. Bu modelde algılanan fayda ve kullanım kolaylığının bilgi sistemleri kabul davranışı ile ilişkili olduğu varsayılmaktadır (Davis vd., 1989). Aşağıdaki şekilde görüldüğü üzere TKM; dışsal değişkenler, algılanan fayda, algılanan kullanım kolaylığı, kullanıma yönelik tutum, davranışa yönelik niyet ve gerçekleşen davranış değişkenlerinden oluşmaktadır.

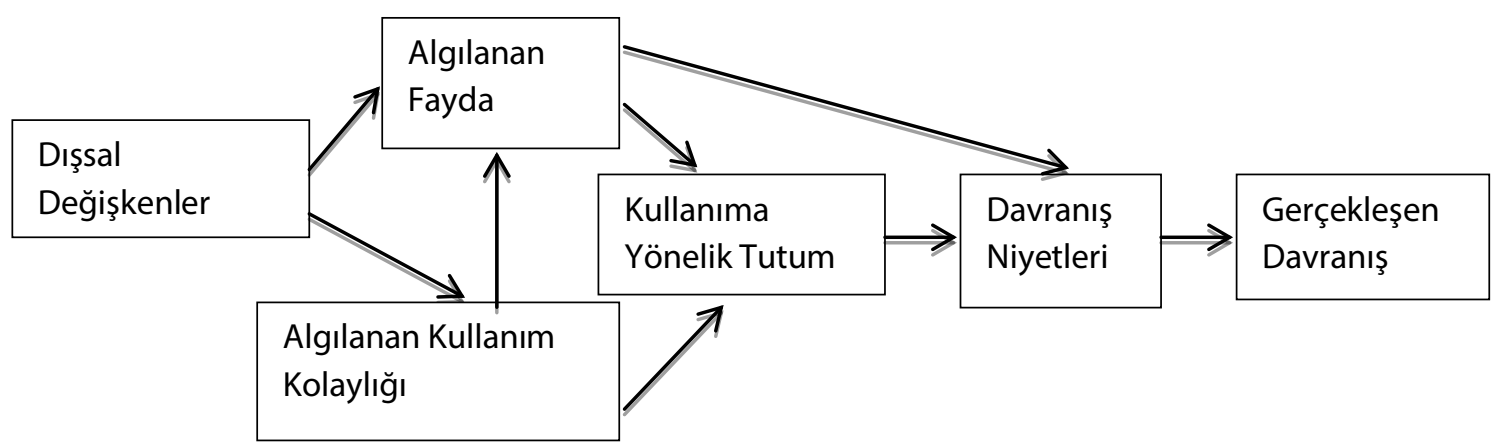

Şekil 1. Teknoloji Kabul Modeli (Davis ve diğ., 1989)

Dışsal değişkenler; bireyin demografik özellikleri (yaş, cinsiyet, eğitim durumu, iş tecrübesi), sistemin teknik özellikleri (menüler, kullanım kılavuzlarının varlığı ve kalitesi), organizasyonel faktörler (işletme büyüklüğü, bilgi teknolojileri bölümünün varlığı, destek elemanların varlığı) ve kullanıcıların teknik 
becerileridir (Aras, 2012). Algılanan kullanım kolaylığı; belli bir teknolojinin kullanımının fazla çaba gösterilmeden öğrenilmesi, kullanımının kolay olmasıdır (Davis,1989). Davis'e göre (1989) algılanan kullanım kolaylığı, tutum ve algılanan fayda üzerinde direkt ve güçlü bir etkiye sahiptir. Algılanan fayda; kişinin bir uygulamanın iş performansını iyileştirmeye yardımcı olduğuna dair inanç düzeyidir (Davis,1989). Sistemin faydalı olduğuna dair inanç sistem kullanımını olumlu yönde etkilemekte, çıktı olarak kaliteli bilgi sahip olmak sistemin faydalı olduğuna dair inancı arttırmaktadır (Lederer vd., 2000). Kullanıma yönelik tutum; olumlu veya olumsuz biçimde tepkide bulunma eğilimidir ve bilgi sistemlerini kullanma niyetini belirleyen önemli bir değişkendir (Ma vd.., 2005). Davis ve arkadaşlarına (1989) göre tutum ve niyet arasındaki ilişki sistem kullanma davranışını olumlu etkiler. Niyet; bir davranışı gerçekleştirmek için bireyin istemleri ve çabalarının göstergesidir (Özer vd., 2010). Bireylerin davranışlarının oluşumunda önemli rol oynayan niyet, tutum tarafından etkilenmektedir (Özer ve Yılmaz, 2010). TKM'de kullanıcıların bilgi sistemlerini kullanma niyeti sistem kullanıcı kabulünü yansıttığı ve kullanım niyetinin sistem kullanma davranışının öncülü olduğu vurgulanmaktadır (Davis vd., 1989).

TKM, bilgi sistemleri literatüründe en çok araştırılan ve alandaki en önemli kabul modelidir (Winkler vd., 2013). Birçok araştırmacı TKM'ini aynı şekilde ya da yeniden düzenleyerek araştırmalarında kullanmıştır. Örneğin, Chtourou ve Souiden (2010) modele eğlence değişkenini, Mekic ve Özlen (2014) güvenlik ve mahremiyet değişkenlerini, Winkler vd. (2013) bilgi kalitesi değişkenini, Lee ve Lohte (2013) ise içerik zenginliği, görev teknoloji uyumluluğu, çeşitlilik gibi değişkenleri ekleyerek modeli test etmiştir.

\section{ARAŞTRMA}

Bu bölümde araştırmanın önemi ve amacı, araştırmanın modeli ve hipotezleri, araştırma yöntemi ve kullanılan ölçekler, analiz bulguları ve yorumlarına verilecektir.

\subsection{Araştırmanın Amacı ve Önemi}

IKKS ile ilgili yapılan çalışmalara bakıldığında daha çok IKBS kullanım durumu (stratejik ya da yönetimsel amaç; idari işler için kullanım), sistemden elde edilen yararlar ve karşılaşılan kısıtlar (Altarawneh ve Al-Shqairat, 2010; Hussein vd., 2007; Ngai ve Wat, 2006; Becker ve Bsat, 2002; Ball, 2001) sistemin başarılı olmasını etkileyen faktörler (Haines ve Petit, 1997; Aras ve Bayraktaroğlu, 2013) üzerinde durulduğu görülmektedir. İKBS'nin TKM ile test edilmesi gerektiği bazı çalışmalarda bahsedilmesine rağmen (Fisher ve Howel, 2004; Voermans ve Van Veldhoven, 2007) Türkiye'de ve uluslararası literatürde IKBS kullanma eğilimini teknoloji kabul modeli ile inceleyen herhangi bir görgül çalışmaya rastlanmamıştır.

Bu çalışmanın amacl, IKBS başarısında önemli bir yeri olan kullanıcıların diğer bir ifade ile insan kaynakları çaIışanlarının IKBS kullanma eğilimini TKM'nden hareketle test etmektir. Bu bağlamda araştırmada TKM'nde dışsal değişkenler (yazılım şirketi IKBS eğitimi, kurum içi IKBS eğitimi, yazılım bilgisi, donanım bilgisi, programlama bilgisi), algılanan fayda, algılanan kullanım kolaylığı, kullanıma yönelik tutum, davranışa yönelik niyet ve gerçekleşen davranış (IKBS kullanımı) değişkenleri arasındaki ilișkiler test edilmiş ve değişkenlerin birbirleri üzerindeki etkileri ortaya konulmuştur. Bu çalışmadan elde edilecek sonuçların literatüre katkı sağlayacağı umulmaktadır. Ayrıca IKKBS'nin başarısında önemli bir yeri olan kullanıcıların eğiliminin belirlenmesi uygulamaya ilişkin de anlamlı olacaktır.

\subsection{Araştırmanın Modeli ve Hipotezleri}

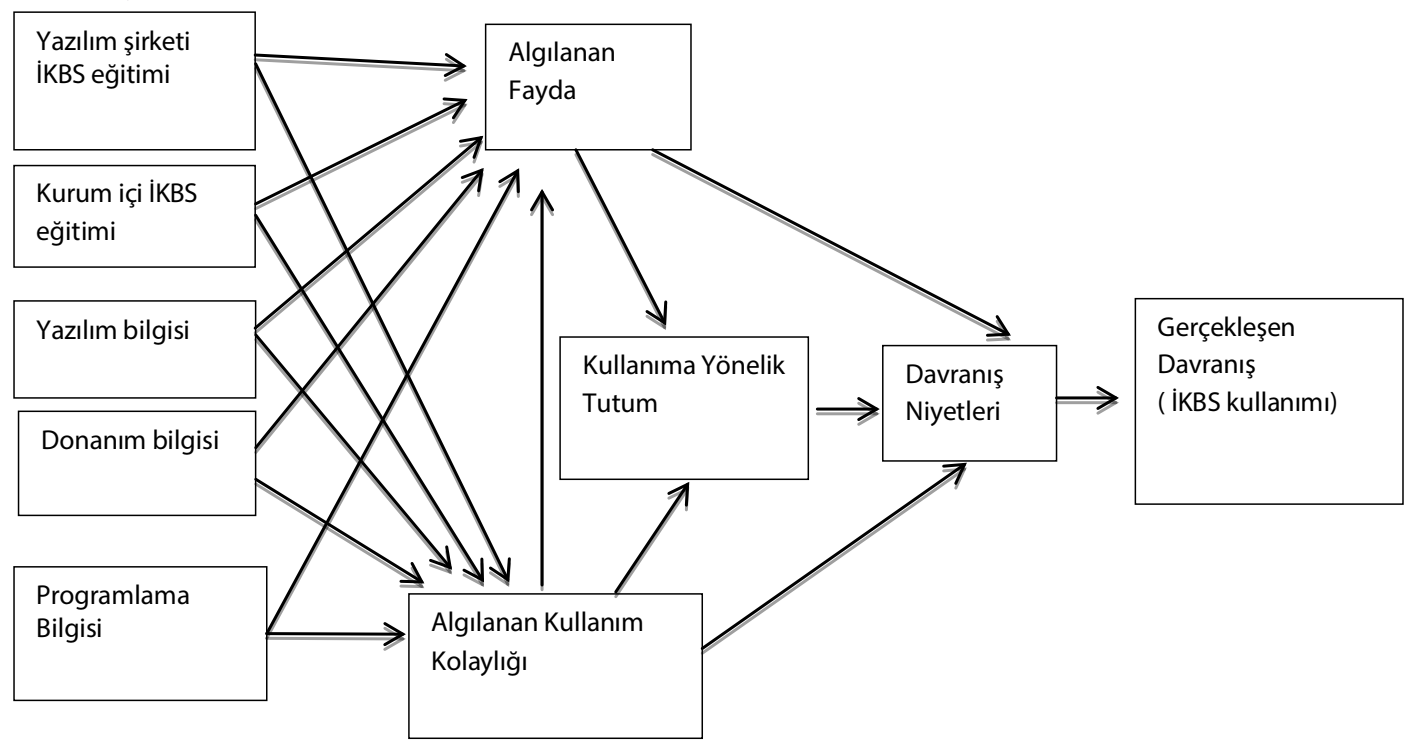

Şekil 2: Araştırma Modeli 
Bu modelde dış değişkenler olarak bilgisayar bileşenleri hakkında bilgi sahibi olma ve IKBS eğitimi ele alınmıştır. Bilgisayar bileşenleri (yazılım, doananım, programlama) hakkında bilgi sahibi olanların sistemden daha fazla tatmin olacağı ve sistemi daha kolay kullanacağı beklenmektedir (Raymond, 1988). Ayrıca IKBS eğitimi alan kullanıcıların sistemden daha fazla yararlanacağı ve sistemi daha fazla kullanacağı ifade edilmiştir (Haines ve Petit, 1997). Bu bilgileden hareketle aşağıdaki hipotezler geliştirilmiştir.

$\mathbf{H}_{1 \mathbf{a}}$ : Yazılım bilgisinin algılanan kullanım kolaylığı üzerinde pozitif etkisi vardır.

$\mathbf{H}_{1 \mathbf{1}}$ :Yazılım bilgisinin algılanan fayda üzerinde pozitif etkisi vardır.

$\mathbf{H}_{2 \mathbf{a}}$ : Donanım bilgisinin algılanan kullanım kolaylığı üzerinde pozitif etkisi vardır.

$\mathbf{H}_{2 \mathbf{b}}$ : Donanım bilgisinin algılanan fayda üzerinde pozitif etkisi vardır.

$\mathbf{H}_{3 \mathbf{a}}$ : Program bilgisinin algılanan kullanım kolaylığı üzerinde pozitif etkisi vardır.

$\mathbf{H}_{36}$ : Program bilgisinin algılanan fayda üzerinde pozitif etkisi vardır.

$\mathbf{H}_{4 \mathbf{a}}$ : Yazılım şirketi İKBS eğitiminin algılanan kullanım kolaylığı üzerinde pozitif etkisi vardır.

$\mathbf{H}_{4 \mathbf{b}}$ : Yazilım şirketi IKBS eğitiminin algılanan fayda üzerinde pozitif etkisi vardır.

$\mathbf{H}_{5 \mathbf{a}}$ : Kurum içi IKBS eğitiminin algılanan kullanım kolaylığı üzerinde pozitif etkisi vardır.

$\mathbf{H}_{56}$ : Kurum içi IKBS eğitiminin algılanan fayda üzerinde pozitif etkisi vardır.

Kullanımı kolay uygulamalar kullanıcılar tarafından daha çabuk benimsenmektedir. Bu yüzden İKBS kullanımının kolay olmasının algılanan faydayı ve sistem tatminini arttırdığı söylenebilir (Seddon, 1997). Burton-Jones ve Hubona (2006) yaptıkları çalışmada kullanım kolaylığının algılanan fayda üzerinde anlamlı etkiye sahip olduğunu tespit etmiştir. Peter vd. (2008) yaptıkları kapsamlı literatür taraması sonucunda kullanım kolaylığı ve algılanan fayda arasında ilişki olduğunu söylemektedir. Cheung ve Vogel (2013) yaptıkları çalışmada kullanım kolaylığı ile algılanan fayda arasında ilişki olduğu sonucuna ulaşmışlardır. Bu bulgulardan hareketle aşağıdaki hipotez oluşturulmuştur.

$\mathbf{H}_{6:}$ Insan kaynakları bilgi sistemlerine yönelik algılanan kullanım kolaylığının algılanan fayda üzerinde pozitif etkisi vardır.

Davis geliştirdiği kabul modelinde tutumun sisteme yönelik kullanım kolaylığı ve algılanan faydadan etkileneceğini varsaymıștır. Jan ve Contreras (2011) üniversitelerde bilgi sistemleri kullanımını TKM ile test etmiş ve algılanan faydanın ve kullanım kolaylığının sisteme yönelik tutumu etkilediği sonucuna ulaşmıştır. Başka bir çalışmada Google uygulamaları ile e-öğrenme konusu TKM ile incelenmiş, algılanan faydanın ve kullanım kolaylığının tutum üzerinde anlamlı etkiye sahip olduğu bulunmuştur (Cheung ve Vogel, 2013). Benzer şekilde Lee ve Lohte (2013) araştırmalarında tutumun algılanan fayda ve kullanım kolaylığını etkilediğini bulmuşlardır. Ayrıca algılanan faydanın sistem kullanım niyeti üzerinde etkili olduğu söylenmektedir (Horton vd., 2001). Bu bulgulardan hareketle geliştirilen hipotezler şu şekildedir;

$\mathbf{H}_{7 \mathbf{a}}$ : Insan kaynakları bilgi sistemlerine yönelik algılanan kullanım kolaylığının tutum üzerinde pozitif etkisi vardır.

$\mathbf{H}_{7 \mathrm{~b}}$ : Insan kaynakları bilgi sistemlerine yönelik algılanan kullanım kolaylığının sistem kullanım niyeti üzerinde pozitif etkisi vardır.

$\mathbf{H}_{8 \mathbf{a}}$ : Insan kaynakları bilgi sistemlerine yönelik algılanan faydanın tutum üzerinde pozitif etkisi vardır.

$\mathbf{H}_{\mathbf{8 b}}$ : Insan kaynakları bilgi sistemlerine yönelik algılanan faydanın sistem kullanım niyeti üzerinde pozitif etkisi vardır.

Tutumun niyet üzerinde etkili olduğunu gösteren birçok çalışma vardır (Özer vd., 2010; Jan ve Contreras, 2011; Cheung ve Vogel, 2013). Tutumun niyet üzerindeki etkisini test etmek amacıyla aşağıdaki hipotez geliştirilmiştir.

$\mathbf{H}_{9}$ : Insan kaynakları bilgi sistemlerinin kullanımına yönelik tutumun niyet üzerinde pozitif etkisi vardır..

E- öğrenmenin kabulunu etkileyen faktörleri araştıran Lee (2006) sistemi kullanma niyetinin sistemi kullanma davranışı üzerinde etkili olduğunu tespit etmiştir. Farklı zaman ve örneklemde yapılan diğer çalışmalarda da sistem kullanım niyetinin, sistem kullanım davranışı üzerinde etkili olduğu sonucuna ulaşılmıştır (Horton vd., 2001; Dasgupta vd., 2002; Jan ve Contreras, 2011; Cheung ve Vogel, 2013; Lee ve Lohte, 2013).

$\mathbf{H}_{10}$ : İnsan kaynakları bilgi sistemlerine yönelik kullanım niyetinin sistem kullanımı üzerinde pozitif etkisi vardır.

\subsection{Araştırmanın Örneklemi}

Farklı sektörlerden binlerce işletmenin yer aldığı önemli bir sanayi bölgesi olması sebebiyle Marmara Bölgesinde faaliyet gösteren işletmelerde çalışan IKBS kullanıcıları araştırmanın evrenini oluşturmaktadır. Araştırmada kolayda örnekleme yöntemi tercih edilmiştir. Marmara bölgesinde faaliyet gösteren işletmelerde kaç tane IKBS kullanıcısı olduğunun bilinmemesi araştırma kısıtını oluşturmaktadır. Araştırma kapsamında 340 tane anket toplanmış 38 anket eksik veri nedeniyle elenmiş ve kalan 302 anket ile araştırma gerçekleştirilmiştir. Katılımcıların \%50,3'ü erkek, $\% 58,6$ 'sı evli, \%71,9'u üniversite mezunu ve \% 44,4'ü 28-37 yaş aralığındadır. Katılımcıların bilgisayar bilgi düzeyine bakıldığında \%39,1 orta derecede yazılım, $\% 44,4^{\prime} u ̈$ orta derecede dananım ve $\% 38,7$ 'si orta de- 
recede programlama bilgisine sahiptir. Katılımcıların $\% 51,4$ 'ü çok az veya orta derecede yazılım şirketinden IKBS eğitimi almış, \%47,3'ü çok az veya orta derecede kurum içi İKBS eğitimi almıştır. Bu bulgulara göre katılımcıların büyük bir kısmı yeterince İKBS eğitimi almamıştır.

\subsection{Araştırmanın Yöntemi ve Kullanılan Ölçekler}

Araştırmada veriler, anket tekniği ile toplanmıştır. Araştırma kapsamında insan kaynakları bilgi sistemleri kullanıcılarının sisteme yönelik algıları TKM ile incelenmiştir. Bu bağlamda Davis (1989) tarafından geliştirilen 6 maddeden oluşan algılanan fayda ölçeği ve 6 maddeden oluşan kullanım kolaylığı ölçeği; Özer vd. (2010) tarafından derlenen 5 maddeden oluşan kullanıma yönelik tutum ölçeği, 7 maddeden oluşan davranış niyeti ölçeği ve 2 maddeden oluşan sistem kullanımı ölçeği kullanılmıştır. Ölçekler $5^{\prime} l i$ Likert (1-kesinlikle katılmıyorum, 5-kesinlikle katılıyorum) yapısındadır. Ayrıca yazılım şirketi IKBS eğitimi 1 madde, kurum içi İKBS eğitimi 1 madde, yazılım bilgisi 1 madde, donanım bilgisi 1 madde ve programlama bilgisi 1 madde ile ölçülmüştür.

\subsection{Araştırma Bulguları}

Bu bölümde araştırma sonucunda elde edilen bulgulara ve yorumlara yer verilmiştir.

Tablo 1: Kullanılan Ölçeklerin Güvenirlik Değerleri

\begin{tabular}{lcc}
\hline Ölçek & ifade Sayısı & Cronbach's Alpha \\
\hline Kullanım kolaylığı & 6 &, 839 \\
Algılanan fayda & 6 &, 927 \\
Tutum & 5 &, 974 \\
Niyet & 7 &, 934 \\
Gerçekleşen davranış & 2 &, 873 \\
\hline
\end{tabular}

Kullanılan ölçeklerin ifade sayısı ve ölçeklere ait güvenirlik kat sayıları tablo 1'de gösterilmiştir. Kullanım kolaylığı için $a=, 839$; algılanan fayda için $a=, 927$; tutum için $a=, 974$; niyet için $a=, 934$ ve gerçekleşen davranış için $a=, 873$ olarak bulunmuştur. Bu değerler ölçeklerin güvenilir olduğunu göstermektedir.

Tablo 2: Faktör Analizi Sonuçları

\begin{tabular}{|c|c|c|c|c|c|}
\hline Toplam açıklanan varyans $\% 72,62$ & KK & $\mathbf{A F}$ & $\mathbf{T}$ & $\mathbf{N}$ & GD \\
\hline İKBS kullanımını öğrenmeyi oldukça kolay buluyorum. & ,809 & & & & \\
\hline İKBS'de istediğim şeyi kolaylıkla yapabiliyorum. & 600 & & & & \\
\hline İKBS ile etkileşimimi kolaylıkla anlıyorum. & 627 & & & & \\
\hline İKBS kullanımını esnek buluyorum. & ,631 & & & & \\
\hline İKBS kullanımında beceri sahibi olmayı kolay buluyorum. & ,758 & & & & \\
\hline Genel olarak IKBS kullanımını kolay buluyorum. & ,716 & & & & \\
\hline İKBS'yi kullanmak iş performansımı arttırıyor & & 766 & & & \\
\hline İKS, görevlerimi daha çabuk yerine getirmemi sağlıyor & & ,762 & & & \\
\hline İKBS'yi kullanmak işteki etkinliğimi arttırıyor. & & 818 & & & \\
\hline İKBS'yi kullanmak üretkenliğimi arttırıyor. & & ,740 & & & \\
\hline İKBS'yi kullanmak işimi yapmamı kolaylaştırıyor. & & 824 & & & \\
\hline Genel olarak, IKKBS'yi kullanmayı işim için yararlı buluyorum. & & ,776 & & & \\
\hline İKBS kullanımını sıkıcı buluyorum. & & & ,932 & & \\
\hline İKBS kullanmak beni gerginleştiriyor. & & & 949 & & \\
\hline İKBS kullanımının bezdirici olduğunu düşünüyorum. & & & 961 & & \\
\hline İKBS kullanmak çok kötü bir fikir. & & & ,957 & & \\
\hline İKBS kullanımını gereksiz buluyorum. & & & ,955 & & \\
\hline Mesleğim söz konusu olduğunda gelecekte de İKBS kullanmaya niyetliyim. & & & & 791 & \\
\hline Bundan sonra mesleğimde IKBS kullanmaya gayret edeceğim & & & & ,848 & \\
\hline İK bilgi sistemlerinde meydana gelecek değişiklikleri uygulamaya çalışacağım. & & & &, 840 & \\
\hline İKBS modülünü gelecekte de kullanacağım. & & & & 872 & \\
\hline İKBS'yi yakın gelecekte düzenli olarak kullanmayı düşünüyorum & & & & ,855 & \\
\hline İKBS'de meydana gelecek yenilikleri takip etmeye çalışacağım. & & & & ,769 & \\
\hline İKS kullanımını meslektaşlarıma ısrarla tavsiye edeceğim. & & & & ,632 & \\
\hline İKBS'yi sık kullanırım. & & & & & 748 \\
\hline İKBS'yi çok sık kullanırım. & & & & & ,764 \\
\hline
\end{tabular}

KK: kullanım kolaylığı; AF: algılanan fayda; T: tutum; N: niyet; GD: gerçekleşen davranış

Ankette kullanılan ölçeklere keşfedici faktör analizi yapılmıştır. Yapılan analiz sonuçları $(\mathrm{KMO}=0,913$; Bartlett test değeri $=6928,736 ; p=, 000$ ) verilerin faktör analizine uygun olduğunu, anakütle içindeki de- ğişkenler arasında bir ilişki olduğunu göstermektedir. Tablo 2'deki bulgulara göre 26 ifade 5 faktörde toplanmıştır ve toplam açıklanan varyans $\% 72,620$ 'dir. Ölçeğin yapı geçerliliğini test etmek için doğrulayıcı 
faktör analizi yapılmıştır. Yapılan doğrulayıcı faktör analizi sonucunda ölçeğin ki-kare istatistiğinin serbestlik derecesine oranı (x2/df) 2,197 (X2=689,741 $\mathrm{df}=314 \mathrm{p}=0,000)$; kök ortalama kare yaklaşım hatası (RMSEA) 0,063; Tucker-Lewis indeksi (TLI) 0,938; uyum iyiliği indeksi (GFI) 0,858; düzeltilmiş uyum iyiliği indeksi (AGFI) 0,828; normlandırılmış uyum indeksi (NFI) 0,904 ve karşılaştırmalı uyum indeksi (CFI) ise 0,945 olarak bulunmuştur. Bu sonuçlar ölçeğin yeterli uyum değerlerine ulaştığını göstermektedir.

Tablo 3: Ortalama, Standart Sapma ve Korelasyonlar

\begin{tabular}{|c|c|c|c|c|c|c|c|c|c|c|c|c|}
\hline & ort. & ss & 1 & 2 & 3 & 4 & 5 & 6 & 7 & 8 & 9 & 10 \\
\hline 1.YŞiKBSE & 2,57 & 1,14 & 1 & & & & & & & & & \\
\hline 2.KilKBSE & 3,25 & 1,07 &, $389^{* * *}$ & 1 & & & & & & & & \\
\hline 3.YB & 2,87 & 1,08 & $347^{* *}$ & $245^{* *}$ & 1 & & & & & & & \\
\hline 4.DB & 3,03 & ,94 &, $321^{* *}$ &, $302^{* *}$ &, $605^{* *}$ & 1 & & & & & & \\
\hline 5.PB & 2,79 & 1,08 &, $309^{* *}$ &, $341^{* *}$ &, $582^{* *}$ &, $593^{* *}$ & 1 & & & & & \\
\hline 6.KK & 3,90 & ,62 & ,209** &, $175^{* *}$ &, $213^{* *}$ & ,159** &, $144^{* *}$ & 1 & & & & \\
\hline 7.AF & 4,27 & ,67 &, $246^{* *}$ &, $352^{*}$ &, $190^{* *}$ &, $236^{* *}$ &, $232^{* *}$ &, $557^{* *}$ & 1 & & & \\
\hline 8.Tutum & 3,44 & 1,40 & ,038 &,- 078 &,- 032 &,- 013 &,- 121 & , 128 & ,067 & 1 & & \\
\hline 9.Niyet & 3,87 &, 51 &, $120^{*}$ &, $216^{* *}$ &, $119^{*}$ &, $171^{*}$ & $079^{* *}$ & ,379* &, $513^{* *}$ &, $060^{*}$ & 1 & \\
\hline 10.GD & 3,85 & 85 &, $115^{*}$ &, $261^{* *}$ & ,047 &, $136^{*}$ &, $117^{* *}$ & ,448 &, $542^{*}$ &, $062^{*}$ &, $511^{* *}$ & 1 \\
\hline
\end{tabular}

** $p<0,01$ anlamlılık seviyesinde ilişki anlamlı ${ }^{*} p<0,05$ anlamlılık seviyesinde ilişki anlamlı

(YŞiKBSE: yazılım şirketi IKBS eğitimi; KilKKSE: kurum içi IKBS eğitimi; YB: yazılım bilgisi; DB: donanım bilgisi; PB: programlama bilgisi; KK: kullanım kolaylığı; AF: algılanan fayda; GD: gerçekleşen davranış)

Tablo 3'te değişkenlere ait ortalama, standart sapma ve korelasyon analizi sonuçlarına yer verilmiştir. Korelasyon analizi sonuçlarına göre yazılım şirketi IKBS eğitimi ile kullanım kolaylığı $(r=, 209)$ ve algılanan fayda $(r=, 246)$; kurum içi İKBS eğitimi ile kullanım kolaylığı $(r=, 175)$ ve algılanan fayda $(r=, 352)$ arasında anlamlı bir ilişski vardır. Benzer şekilde yazılım bilgisi ile kullanım kolaylığı $(r=, 213)$ ve algılanan fayda $(r=, 190)$; donanım bilgisi ile kullanım kolaylığı $(r=, 159)$ ve algılanan fayda $(r=, 236)$ ve programlama ile kullanım kolaylığı $(r=, 144)$ ve algılanan fayda $(r=, 232)$ arasında anlamlı bir ilişki vardır. Modeldeki diğer değişkenler olan; kullanım kolaylığı ile algılanan fayda $(r=, 557)$, kullanım kolaylığı ile niyet $(r=, 379)$, algılanan fayda ile niyet $(r=, 513)$, tutum ile niyet $(r=, 060)$ ve niyet ile gerçekleşen davranış $(r=, 511)$ arasında anlamlı ilişki vardır. Bu bulgular önceki çalışmaları desteklemektedir (Özer vd., 2010; Winkler vd., 2013). Kullanım kolaylığı ve algılanan fayda ile tutum arasında ise bir ilişkiye rastlanmamıştır.

\subsection{Hipotezlerin Testi}

Değişkenler arasındaki etkiyi incelemek için regresyon analizi yapılmıştır. Analiz bulgularına göre; yazılım şirketi İKBS eğitimi kullanım kolaylığı $(F=13,318$, $\left.R^{2}=, 040, p=, 000, \beta=, 209\right)$ ve algılanan fayda $(F=18,824$, $\left.R^{2}=, 057, p=, 000, \beta=, 246\right)$ üzerinde anlamlı etkiye sahiptir. Benzer şekilde kurum içi İKBS eğitimi kullanım kolaylığı $\left(F=9,273, R^{2}=, 027, p=, 003, \beta=, 175\right)$ ve algılanan fayda ( $\left.F=41,673, R^{2}=, 121, p=, 000, \beta=, 352\right)$ üzerinde anlamlı etkiye sahiptir. Yani yazılım şirketi ve kurum içi IKBS eğitimleri arttıkça algılanan kullanım kolaylığı ve algılanan fayda artmaktadır. Bilgisayar bileşenleri hakkındaki bilgilerin kullanım kolaylığı ve algılanan fayda üzerindeki etkisine bakılmıştır analiz sonuçlarına göre yazılım bilgisi kullanım kolaylığı $(F=13,968$,
$\left.R^{2}=, 042, p=, 000, \beta=, 213\right)$ ve algılanan fayda $(F=11,086$, $\left.R^{2}=, 033, p=, 001, \beta=, 190\right)$ üzerinde; donanım bilgisi kullanım kolaylığı $\left(F=7,693, R^{2}=, 022, p=, 006, \beta=, 159\right)$ ve algılanan fayda $\left(F=17,369, R^{2}=, 052, p=, 000, \beta=, 236\right)$ üzerinde; programlama bilgisi kullanım kolaylığı $\left(F=6,254, R^{2}=, 017, p=, 013, \beta=, 144\right)$ ve algılanan fayda $\left(F=16,821, R^{2}=, 051, p=, 000, \beta=, 232\right)$ üzerinde anlamlı etkiye sahiptir. Bu bilgilere göre bilgisayar bileşenleri hakkında daha fazla bilgi sahibi olanlar sistem kullanımını kolay bulmakta ve sistemden daha fazla fayda sağlamaktadırlar. Ayrıca kullanım kolaylığı, algılanan fayda üzerinde $\left(F=134,883, R^{2}=, 308, p=, 000, \beta=, 557\right)$ anlamlı etkiye sahiptir. Sistem kullanımını kolay bulan kullanıcılar sistemden daha fazla fayda elde etmektedirler. Kullanım kolaylığı ve algılanan faydanın tutum üzerindeki etkisine bakılmış ve bulgulara göre kullanım kolaylığı tutum üzerinde $\left(F=5,00, R^{2}=, 013\right.$, $p=, 026, \beta=, 128)$ anlamlı etkiye sahip iken algılanan fayda tutum üzerinde $\left(F=1,364, R^{2}=, 001, p=, 244\right.$, $\beta=, 067)$ anlamlı bir etkiye sahip değildir. Benzer şekilde tutumun niyet üzerinde $\left(F=1,082, R^{2}=, 000, p=, 299\right.$, $\beta=, 060$ ) etkili olmadığı sonucuna ulaşılmıştır. Her ne kadar yapılan araştırmada tutum niyet üzerinde etkili olmasa da algılanan fayda niyet üzerinde ( $F=100,990$, $\left.R^{2}=, 260, p=, 000, \beta=, 513\right)$ ve kullanım kolaylığı niyet üzerinde $\left(F=50,333, R^{2}=, 141, p=, 000, \beta=, 379\right)$ anlamlı etkiye sahiptir. Son olarak niyetin gerçekleşen davranış üzerindeki etkisine bakılmış ve niyetin gerçekleşen davranış üzerinde $\left(F=106,069, R^{2}=, 259, p=, 000\right.$, $\beta=, 511$ ) anlamlı etkisi olduğu sonucuna ulaşılmıştır. Bu bulgulara göre $\mathbf{H}_{8 \mathrm{a}}$ ve $\mathbf{H}_{9}$ dışındaki tüm hipotezler kabul edilmiştir. 


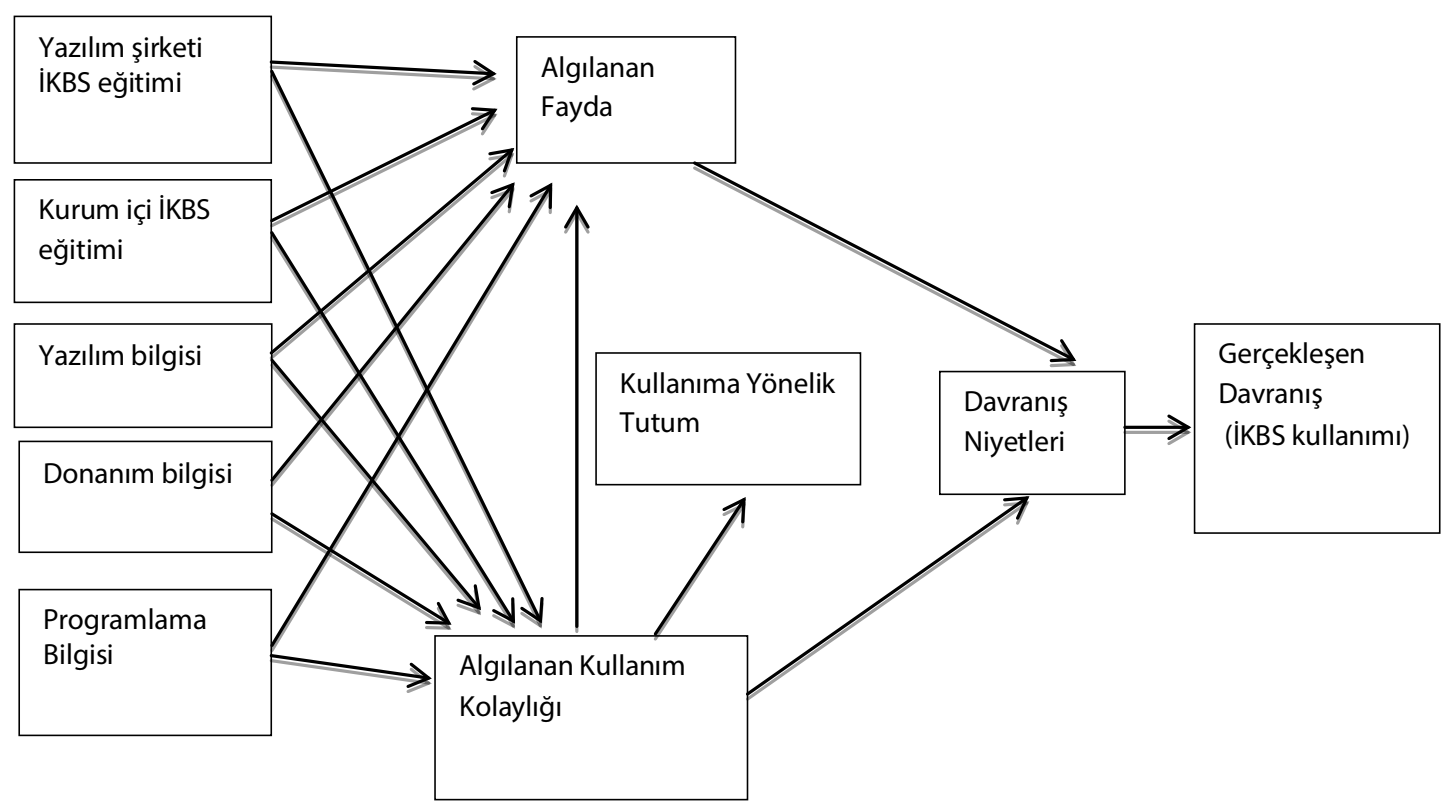

Şekil 3: Araştırma Modelinin Son Hali

\section{SONUÇ VE ÖNERILER}

İşletmelerde kullanılan bilgi sistemleri rutin işlerin daha hızı yapılmasını ve stratejik işlere daha fazla zaman ayrılmasını sağlamaktadır. Bilgi sistemlerinin birçok yararı olmasına rağmen kullanıcılar bu sistemlere karşı direnç göstermekte ve istenilen seviyede sistemlerden faydalanmamaktadırlar. Kullanıcılar sistemi kullanmaya istekli olduklarında sistem başarısı ve arzulanan fayda gerçekleşir ancak bunun tam tersi bir durum ise sistemin kabul edilmediğine dair bir işaret olarak kabul edilebilir.

Bu çalışmada, kullanıcıların insan kaynakları bilgi sistemlerine yönelik algıları teknoloji kabul modelinden hareketle araştırılmıştır. Dış değişken olarak yazıIım şirketi IKBS eğitimi, kurum içi IKBS eğitimi, yazılım bilgisi, donanım bilgisi ve programlama bilgisi ele alınmış bu değişkenlerin algılanan fayda ve algılanan kullanım kolaylığı değişkenlerini pozitif şekilde etkilediği sonucuna ulaşılmıştır. Bilgisayar bileşenleri hakkında bilgi sahibi olanlar sistemi daha kolay kullanmakta ve sistemden elde ettikleri fayda artmaktadır. Ayrıca bu araştırma sonucu bir kere daha göstermektedir ki sistemden daha fazla verim elde etmek için yazılım şirketi IKBS eğitimi ve kurum içi İKBS eğitimlerine daha fazla önem verilmelidir.

Insan kaynakları bilgi sistemlerinin kullanıc dostu olması yani kullanımının kolay olması sistemden elde edilen faydayı arttırmaktadır. Bu bulgu diğer çalışmaları desteklemektedir (Peter vd., 2008; Cheung ve Vo- gel, 2013). Bunun nedeni kullanımı kolay olan sistemlere karşı daha az direnç oluşmasıdır. Sistemin kolay kullanıldığı ve faydalı olduğu algısı sistem kullanımına yönelik niyeti pozitif yönde etkilemekte ve sisteme yönelik iyi niyet sonucunda insan kaynakları bilgi sistemleri kullanımı artmaktadır. Bu bulgular literatürdeki bulguları desteklemektedir (Horton vd., 2001; Jan ve Contreras, 2011; Cheung ve Vogel, 2013; Lee ve Lohte, 2013). Literatürde tutumun niyet üzerinde etkili olduğunu vurgulayan birçok çalışma olmasına rağmen (Özer vd., 2010; Jan ve Contreras, 2011; Cheung ve Vogel, 2013) bu çalışmada tutumun niyet üzerindaki etkisi tespit edilememiştir. Sistem kabulünde kolay kullanım ve fayda sağlama sistem kullanımını büyük oranda şekillendirmektedir. Bu yüzden sistem sağlayıcılar daha hızlı, kullanıcı dostu ve maksimum faydayı verecek sistemler tasarlamalı; yöneticiler IKBS eğitimine gereken önemi vermeli; kullanıcılar ise sisteme direnç göstermeyerek verilen eğitimlere önem vermelidirler.

Bilgi sistemleri kabulünde genelde algılanan fayda ve kullanım kolaylığı değişkenleri ana değişken olarak alınmaktadır. Gelecek çalışmalarda, bu değişkenlere ek olarak bilgi kalitesi, sistem kalitesi, içerik zenginliği vb. değişkenler araştırılarak bu değişkenlerin bilgi sistemleri kabulündeki etkileri araştırılabilir. Ayrıca insan kaynakları bilgi sistemleri kullanımı ve bireysel performans arasındaki ilişki araştırılabilir. 


\section{KAYNAKLAR}

Altarawneh, I. ve Z. Al-Shaqairat. (2010) "Human Resource Information Systems in Jordanian University" International Journal of Business and Management, 5(10): 113-127.

Aras, M. (2012) "İnsan Kaynakları Bilgi Sistemlerinin Başarısında Rol Oynayan Faktörler: Bir Araştırma” Yayınlanmamış Yüksek Lisans Tezi, Sakarya, Sakarya Üniversitesi SBE.

Aras, M. ve Bayraktaroğlu, S. (2013) "İnsan Kaynakları Bilgi Sistemlerinde Kullanıcı Bilgi Tatmini: Sistemsel Değişkenlerin Etkisi” Sakarya İktisat Dergisi, 1(5):166192.

Ball, K. S. (2001) "The Use of Human Resource Information Systems” Personnel Review, 30 (6): 677-693.

Bayraktaroğlu, S. ve Tunçbilek, M..(2002) “Bilgi Toplumunda İKY’nin Değişen Yüzü” Kocaeli Üniversitesi, 1.Ulusal Bilgi, Ekonomi ve Yönetim Kongresi Bildiriler Kitab1.

Beadles II, N., A. Lovery, M. Christopher ve Johns, K. (2005) "The Impact of Human Resource Information Systems: An Exploratory Study in the Public Sector" Communications of the IIMA, 5(4).

Beckers, A. M. ve M. Z. Bsat. (2002) "A DSS classification model for research in human resource information systems" Information Systems Management, 19(3): 41-50.

Burton-Jones, A. ve Hubona, G. S. (2006) "The mediation of external variables in the technology acceptance model" Information \& Management, 43(6): 706-717.

Chandra, R. P. (2009) "Role of HRIS in improving Modern HR operations" Advances In Management, 2(12): 21-24.

Cheung, R. ve Vogel, D. (2013) "Predicting user acceptance of collaborative technologies: An extension of the technology acceptance model for e-learning" Computers \& Education, 63: 160-175.

Chtourou, M.S. ve Souiden, N. (2010) "Rethinking the TAM model: time to consider fun" Journal of Consumer Marketing, 27(4): 336-344.

Dasgupta, S. Granger, M. ve McGarry, N. (2002) "User Acceptance of E-Collaboration Technology: An Extension of the Technology Acceptance Model" Group Decision and Negotiation, 11:87-100.

Davis, F. D. (1985) “A Technology Acceptance: Model for Empirically Testing New End User Information Systems: Theory and Results", Doctoral dissertation, Sloan School of Management, Massachusetts Institute of Technology.

Davis, F. D. (1989) "Perceived Usefulness, Perceived Ease of Use and User Acceptance of Information Technology” MIS Quarterly, September: 319-340.

Davis, F. D. ve Venkatesh, V. (2004) “Toward preprototype user acceptance testing of new information systems: implications for software project management" IEEE Transactions on Engineering Management, 51(1): 3146.

Davis, F.D., Bagozzi, R.P. ve Warshaw, P.R. (1989) "User Acceptance of Computer Technology: A Comparison of Two Theoretical Models" Management Science, 35(8): 982-1003.

Fisher, S.L., ve Howell, A.W. (2004) "Beyond User Acceptance: An Examination of Employee Reactions to Information Technology Systems" Human Resource Management, 43: 243-258.

Haines, V. Y ve A. Petit. (1997) "Conditions for successful human resource information systems" Human Resource Management, 36(2): 261-275.

Horton, R.P., Buck, T. Waterson, P. E. ve Clegg, C.W. (2001) "Explaining intranet use with the technology acceptance model" Journal of Information Technology, 16(4): 237-249.

Hussein, Z., J. Wallace ve N.E. Cornelius. (2007) "The use and impact of human resource information systems on human resource management professionals" Information and Management, 44: 74-89.

Jan, A. ve Contreras, V. (2011) “Technology acceptance model for the use of information technology in universities" Computers in Human Behavior, 27(2): 845-851.

Kovach, K. A ve Cathcart, C. E. (1999) "Human Resource Information Systems (HRIS): Providing Business with Rapid Data Access, Information Exchange and Strategic Advantage" Public Personnel Management, 28(2): 275-282.

Lederer, A. L., Maupin, D.J., Sena, M. P., ve Zhuang, Y. (2000) "The technology acceptance model and the World Wide Web” Decision Support Systems, 29(3): 269-282.

Lee, Y. (2006) "An empirical investigation into factors influencing the adoption of an e-learning system" Online Information Review, 30(5): 517-541.

Lee, D.Y. ve Lohte, M.R. (2013) "User acceptance of YouTube for procedural learning: An extension of the Technology Acceptance Model" Computers \& Education, 61: 193-208.

Lengnick-Hall, M. L. ve Moritz, S. (2003) "The Impact of e-HR on the Human Resource Management Function" Journal of Labor Research, 24(3): 365-379.

Ma, W.W., Anderson, R. ve Streith, K.O. (2005) "Examining User Acceptance of Computer Technology: an Empirical Study of Student Teachers, Journal of Computer Assisted Learning, 2: 387-395.

Martinsons, M. G. ve Chong, P.K.C. (1999) "The Influence of Human Factors and Specialist Involvement on Information Systems Success" Human Relations, 52(1): 123-152.

Mekic, E. ve Özlen, M.K. (2014) "Acceptance of 
Smartphones by Users in BİH Through Extended Technology Acceptance Model" European Researcher, 67(1-2): 136-150.

Ngai, E.W.T ve Wat, F.K.T. (2006) "Human resource information systems: a review and empirical analysis" Personnel Review, 35(3): 297-314.

Özer, G. ve Yılmaz, E. (2010) "Mantıklı Eylem Teorisi (MET) ile Muhasebecilerin Bilgi Teknolojisi Kullanımına Yönelik Bir Uygulama” İktisat, İsletme ve Finans, 25: 65-88.

Özer, G., Özcan, M., ve Aktaş, S. (2010) "Muhasebecilerin Bilgi Teknolojisi Kullanımının Teknoloji Kabul Modeli ile İncelenmesi” Journal of Yaşar University, 5(19):3278-3293.

Petter, S., DeLone, W., ve McLean, E. (2008) "Measuring Information Systems Success: Models, Dimensions, Measures, and Interrelationships" European Journal of Information Systems, 17:236-263.
Raymond, L. (1988) "The impact of computer training on the attitudes and usage behavior of small business manager" Journal of Small Business Manager, 26(3): 8-13.

Seddon, P.B. (1997) "A Respecification and Extension of the DeLone and McLean Model of IS Success" Information System Research, 8: 240-253.

Tannenbaum, S. (1990) "Human Resource Information Systems: User Group Applications" Journal of Systems Management, 41(1):27-32.

Voermans, M., ve Van Veldhoven, M. (2007) "Attitude towards E-HRM: An Empirical Study at Philips" Personnel Review, 36: 887-902.

Winkler, S., König, C.J. ve Kleinmann, M. (2013) "What makes human resource information successful? Mangers perceptions of attributes for successful human resource information" International Journal of Human Resource Management, 24(2): 227-242. 
